\title{
Mercados y derechos globales: implicancias para los pueblos indígenas de América Latina y Canadá
}

\author{
José Aylwin Oyarzún*
}

\begin{abstract}
RESUMEN
En este artículo se analizan las implicancias que las diferentes manifestaciones de la globalización hoy en curso - la del mercado, expresada en acuerdos comerciales y en la proliferación de las inversiones de las industrias extractivas, y aquella referida al reconocimiento internacional de los derechos humanos-están teniendo para los pueblos indígenas de América Latina y Canadá. Se describen los impactos generados en los territorios indígenas por las actividades de empresas extractivas, muchas de ellas canadienses, impulsadas sin el consentimiento libre, previo e informado de las comunidades, sin su participación en los beneficios o compensación por daños. Se argumenta que el nuevo escenario jurídico resultante de la globalización de los derechos referidos a las personas y a los pueblos, incluyendo a los pueblos indígenas, obligará a los Estados de la región y a Canadá a revisar sus marcos normativos y políticas referidos a las inversiones en territorios indígenas para garantizar su respeto.
\end{abstract}

Globalización - acuerdos comerciales - pueblos indígenas

\section{Global markets and global rights: implication for the indigenous people from Latin America and Canada}

\begin{abstract}
This article analyzes the implications that the different expressions of globalization -that of markets manifested in trade agreements and in the proliferation of extractive industries' investments, and that referred to the international recognition of human right-are having
\end{abstract}

* Abogado, profesor del Curso de Derecho Indígena de la Facultad de Ciencias Jurídicas y Sociales Universidad Austral de Chile y Codirector del Observatorio Ciudadano. Este artículo fue presentado como ponencia en el panel Canada in the Americas del Congreso de CALACS 2012, Between Indigeneity and the Transnational: Place and Mobility in Latin America and the Caribbean, realizado en Kelowna, Canadá, en mayo de 2012. La elaboración de este artículo fue posible gracias al apoyo del gobierno de Canadá por medio de su programa Understanding Canada-Canadian Studies Program. A su realización también colaboró la Fundación Ford e IWGIA de Dinamarca. Agradezco la lectura y comentarios de Viviane Weitzner, Jennifer Moore de Mining Watch Canada, y de Anne Catherine Kennedy de Desarrollo y Paz, Canadá. La responsabilidad de las opiniones contenidas en este artículo es exclusivamente del autor. Correo Electrónico: jaylwin@observatorio.cl

Artículo recibido el 30 de marzo de 2013 y aceptado para su publicación por el Comité Editorial el 28 de octubre de 2013. 
for indigenous peoples in Latin America and Canada. The impacts generated by the activities undertaken by these industries, many of them Canadian, on indigenous lands and territories, both in Latin America and in Canada, without free prior informed consent of the communities affected, without their participation on benefits, and without compensation for damages, are described. We argue that the new legal scenario which has emerged with the globalization of human rights, will oblige Canada and Latin American states to revise their legal framework and policies referred to the activities of these industries on indigenous lands and territories, in order to ensure the respect for the rights of indigenous peoples.

Globalization - trade agreements - indigenous people

\section{INTRODUCCIÓN}

$\mathrm{L}$ a globalización es un proceso complejo y multifacético, que tiene diferentes dimensiones. Ella se manifiesta en procesos de liberalización de los mercados y de apertura creciente de las fronteras estatales a los flujos de capital e inversiones, los que han facilitado el comercio internacional. Tal globalización ha contribuido a la conformación de una economía mundializada controlada por grandes conglomerados, generalmente originados en los países del norte. Por otro lado, ella se manifiesta también en consensos básicos de los Estados que han dado lugar a la construcción de un derecho supraestatal relativo a los derechos de las personas y de los pueblos. A los acuerdos logrados por la comunidad internacional con posterioridad a la Segunda Guerra Mundial, manifestados en la Declaración Universal de Derechos Humanos en 1948, y más tarde, en 1966, en los Pactos complementarios de derechos civiles y políticos, y de derechos económicos, sociales y culturales, se agregan hoy otros nuevos expresados en convenciones y directrices internacionales referidos a problemáticas emergentes, como el desarrollo y la protección del medio ambiente, o a sectores de la población marginados en el ejercicio de sus derechos individuales, como las mujeres, los niños los migrantes.

Como parte de estos últimos consensos de derechos humanos es que la comunidad internacional ha reconocido progresivamente la especificidad y derechos colectivos de los pueblos indígenas, mediante instrumentos como el Convenio 169 de la Organización Internacional del Trabajo (OIT) de 1989, y la Declaración de las Naciones Unidas sobre Derechos de los Pueblos Indígenas de 2007 (DNUDPI). Estos instrumentos reconocen a los pueblos un conjunto de derechos políticos -como la libre determinación y la autonomía, la consulta y el consentimiento libre, previo e informado (CLPI) frente a medidas administrativas y legislativas que les afecten directamente, como son los proyectos de inversión extractivos-, así como de derechos territoriales, incluyendo entre ellos los derechos de propiedad y posesión sobre sus tierras, territorios y recursos naturales ancestrales.

Estas dos dimensiones de la globalización -la del mercado y la de los derechos humanos- como veremos a continuación, se reflejan de manera nítida en los casos de América Latina y Canadá, donde tanto el intercambio comercial como la regulación normativa referida a los derechos de las personas y de los pueblos indígenas han tenido 
un desarrollo creciente en las últimas décadas. A continuación analizaremos algunas de las manifestaciones, así como también las tensiones, de estos dos procesos globalizadores en desarrollo, así como sus implicancias para los pueblos indígenas en ambos contextos.

\section{LA APERTURA DE LOS MERCADOS Y EL ROL EMERGENTE de Canadá en América latina}

Promovido por Estados Unidos, el libre comercio ha ganado creciente espacio en las Américas. Luego de que en 1988 se firmara el Tratado de Libre Comercio (TLC) entre ese país y Canadá, en 1992 se suscribió el Tratado de Libre Comercio de Norteamérica (NAFTA por su sigla en inglés), el que incorporó a México como socio comercial ${ }^{1}$. Más tarde, luego del fracaso del Área de Libre Comercio de las Américas (ALCA) promovida por Bush (H.W.) a mediados de los noventa, el gobierno de Estados Unidos decidió proseguir su agenda negociando TLC bilaterales o subregionales con diferentes Estados. Es así como desde entonces ha suscrito TLC con Chile (2004), Costa Rica, El Salvador, Guatemala, Honduras y Nicaragua (CAFTA) (2004), Perú (2006), y más tarde con Panamá y Colombia ${ }^{2}$, todos ellos de similares contenidos destinados a facilitar el comercio y las inversiones entre los Estados suscriptores.

Con posterioridad al NAFTA, Canadá expandió sus alianzas de libre comercio en la región, suscribiendo en 1997 el TLC con Chile. En lo central el TLC Canadá-Chile (CCFTA), cuyo contenido era muy similar a los TLC suscrito por Chile con Estados Unidos, trató no solo sobre comercio e inversiones, sino también incluyó acuerdos de cooperación en materia laboral y en materia ambiental. Con posterioridad Canadá suscribió un TLC con Costa Rica (CCRFTA), que entró en vigencia el 2002, y con Perú (PCFTA), el que entró en vigencia el 2009. Acuerdos adicionales han sido suscritos por Canadá con Colombia el 2008³, el que entró en vigor el 2011, y con Panamá el 2010, el que aún no entra en vigencia.

Como consecuencia de estos acuerdos comerciales en algunos casos (México, Chile y Costa Rica), o en forma independiente de ellos en otros casos, la inversión directa de Canadá en América Latina creció rápidamente durante este período. El valor total de las inversiones de compañías canadienses en la región se duplicó en el periodo 20032007, incrementándose de US\$18,3 billones a US\$37,4 billones. La inversión directa

${ }^{1}$ El 1 de enero de 1994, el día en que el NAFTA entró en vigencia, el Ejército Zapatista de Liberación Nacional (EZLN), organización que reunía a pueblos indígenas del sur de México, tomó las armas en Chiapas para manifestar su repudio a este acuerdo y demandar del gobierno mexicano derechos de autonomía y la libre determinación.

${ }^{2}$ Ambos tratados fueron aprobados por el Congreso de EE.UU. el 2011. El TLC con Colombia entrará en vigencia el 15 de mayo de 2012.

${ }^{3}$ Este TLC incluye no solo un acuerdo de colaboración en materia ambiental y otro en materia laboral, sino también de evaluación anual por ambos gobiernos en materia de derechos humanos. La evaluación crítica de la situación de derechos humanos en Colombia, sin embargo, no ha sido obstáculo para la continuación de las inversiones de empresas canadienses en ese país. 
canadiense en la región se ha concentrado en la extracción y procesamiento de recursos naturales, incluyendo los minerales metálicos, la madera y en el sector de la energía. Las inversiones mineras se han concentrado principalmente en México, Chile, Brasil, Argentina y Perú, siendo la minería la única actividad en que América Latina es la región más relevante para la inversión externa directa canadiense ${ }^{4}$. El 2009 la inversión de las compañías mineras canadienses en la región fue de US $\$ 1,7$ billones, equivalente al 32\% de la exploración total en la región. El $50 \%$ de dicha inversión se focalizó en México y Chiles.

En el caso de México, y de acuerdo con la Cámara Minera de México, el $87 \%$ de las inversiones mineras son canadienses. Muchas de ellas han afectado tierras de comunidades indígenas, contaminando sus aguas y alterando drásticamente sus economías agrícolas ${ }^{6}$. En el caso de Chile, las inversiones canadienses alcanzan al $24 \%$ de la inversión externa total en el periodo comprendido entre 2002 y el $2011^{7}$. Un porcentaje significativo de esta inversión (62\%) desde que el CCFTA entró en vigor en 1997 ha sido en el sector minero (Gobierno de Chile, 2008). Gran parte de la minería se desarrolla en el norte de Chile, en el territorio ancestral de los pueblos indígenas andinos en el norte del país. Una de las compañías canadienses involucradas en la minería en Chile, Barrick Gold, ha llevado adelante un proyecto aurífero en la mina Pascua Lama en violación de los derechos de propiedad ancestral de la comunidad diaguita de Huasco Alto. El proyecto, cuya inversión es hoy estimada en US $\$ 8$ billones $^{8}$, y que se expande hacia territorio argentino, fue aprobado por las autoridades de Chile sin un proceso de consulta de la comunidad diaguita. A la fecha ha impactado los glaciares que nutren los cursos de aguas de la comunidad, provocando serios daños a la economía tradicional. También ha resultado en la contaminación de dichas aguas, así como en la destrucción de las tierras de pastoreo 9 .

Otro proyecto para la explotación de cobre y oro, con una inversión superior a los US\$2.500 millones, de responsabilidad de la empresa canadiense Goldcorp, fue

${ }^{4}$ Arellano, J. M., Canadian Foreign Direct Investment in Latin America, The North South Institute, Ottawa, 2010. Disponible en http://www.nsi-ins.ca/english/pdf/FDI\%20backgrounder.pdf [consultada el 10 de marzo de 2012].

${ }^{5}$ Drake, A., Overview of trends in Canadian minerals exploration, Natural Resources Canada, Ottawa, 2010, citado en Weitzner, V., Inclinando la balanza del poder. Logrando que el consentimiento libre, previo e informado funcione, North South Institute, Ottawa, 2011.

${ }^{6}$ Ross, J., "Canadian mining companies undermining Mexico”, 2009. Disponible en http://mostlywater. org/canadian_mining_companies_undermining_mexico [consultada el 18 de marzo de 2012]

${ }^{7}$ Peña, N., "Canadá desplaza a EE.UU. como mayor inversor en Chile en última década", en La Tercera, enero 28, 2012, p. 55.

${ }^{8}$ Ver http://www.mineweb.com/mineweb/view/mineweb/en/page34?oid=155905\&sn=Detail. [consultada el 15 de abril de 2012]

${ }^{9}$ La comunidad, que no ha sido compensada por los daños provocados por la minería, recurrió a la Comisión Interamericana de Derechos Humanos (CIDH), alegando la violación por el Estado chileno de, entre otros derechos, la propiedad y la igualdad ante la ley al haber aprobado el proyecto de Barrick Gold. Ver denuncia de comunidad ante CIDH en http://www.monitoreandoderechos.cl/ficha/133 [consultada el 13 de abril de 2012]. 
aprobado el 2011. Dicho proyecto, conocido como El Morro, se asienta también sobre tierras de propiedad ancestral de la misma comunidad diaguita. Recientemente, en mayo de 2012, la Corte Suprema acogió un recurso de protección interpuesto por la comunidad y ordenó anular la resolución que aprobó su estudio de impacto ambiental debido a la violación de los derechos del Convenio 169 de la OIT sobre Pueblos Indígenas y Tribales en Países Independientes (en adelante Convenio 169), entre ellos, el deber de consulta de los pueblos indígenas, el derecho a participar en los beneficios y a percibir una indemnización por los daños causados ${ }^{10}$.

En el caso de Perú, las inversiones de empresas canadienses en la minería y en explotación de hidrocarburos son también significativas. El oro y otros metales preciosos constituían más del 53\% del total de las exportaciones de Perú a Canadá el $2007{ }^{11}$. Aunque el porcentaje de participación en la inversión canadiense en estos ámbitos ha disminuido, ambos sectores siguen representando el $31 \%$ de las inversiones de Canadá en ese país ${ }^{12}$. A la fecha más de 200 compañías, la mayoría de ellas canadienses, están explorando petróleo, gas y otros recursos naturales hoy en Perú ${ }^{13}$. La Defensoría del Pueblo de ese país estima que la mayoría de los conflictos sociales tienen su origen en problemas ambientales. Entre ellos la minería representa el $68 \%$ del total de conflictos y los hidrocarburos representan el $11 \%$ de los mismos. ${ }^{14}$

Otro país en que la minería canadiense ha generado conflictos significativos es Guatemala. Un ejemplo es el de la mina Marlin, de propiedad de una subsidiaria de Goldcorp de Canadá. La minera inició sus actividades el 2005, sin procesos de consulta a las comunidades indígenas de conformidad con los estándares internacionales ${ }^{15}$. Los impactos de la actividad minera en las comunidades indígenas, en especial en el agua, y en los derechos de los defensores, y la ausencia de consulta, llevaron a la OIT el 2010

${ }^{10}$ Sentencia de 27 de abril de 2012, Corte Suprema de Chile (causa Rol No 2211-2012). En razón de esa sentencia Goldcorp anunció la paralización de sus faenas.

11 Randall, J.C., "Canada, the Caribbean and Latin America: Trade, Investment and Political Challenges," en Canadian International Council, agosto, 2010. Disponible en http://www.opencanada.org/wp- content/ uploads/2011/05/Canada-the-Caribbean-and-Latin-America_-Trade-Investment-and-Political-ChallengesStephen-J.-Randall.pdf. [consultada el 13 de marzo de 2012].

12 De Echave, J., ¿Invitados a la mesa grande? El crecimiento del sector extractivo, la participación indígena/campesina en procesos multiactorales y presencia canadiense en el Perú. Cooper Action, Lima; North South Institute, Ottawa, 2011. Disponible en http:/www.nsi-ins.ca/images/documents/peru_spanish_2011_final_web.pdf [consultada el 2 de abril de 2012].

13 Durante el 2008 las compañías canadienses en Perú fueron responsables de diversos eventos con consecuencias negativas para las comunidades, incluyendo la intrusión en tierras de comunidades no contactadas; la destrucción de sitios precolombinos; la contaminación de aguas ( Engler, Y., "Canada's New Territory? Mining Peru”, 2010. Disponible en http://www.counterpunch.org/2010/12/23/mining-peru/ [consultado el 20 de marzo de 2012]).

${ }^{14}$ De Echave, J. op. cit.

${ }^{15}$ En un plebiscito efectuado ese año en el municipio de Sipacapa, uno de los dos donde la mina fuera establecida, el 98\% de los votantes rechazó el proyecto. Lo mismo habían hecho previamente 11 de las 13 comunidades del área. 
a requerir al gobierno de ese país la suspensión de la explotación ${ }^{16}$. El mismo año la Comisión Interamericana de Derechos Humanos (CIDH) aprobó una medida cautelar a favor de 18 comunidades maya pidiendo al gobierno de Guatemala suspender las operaciones de la mina y garantizar agua potable no contaminada a las comunidades, atender a su salud, y garantizar su seguridad física ${ }^{17}$. El gobierno de Guatemala, sin embargo, nunca implementó las medidas ${ }^{18}$.

La ausencia de consentimiento libre, previo e informado, de compensación por daños, así como de participación en los beneficios por parte de comunidades indígenas y afrodescendientes impactadas por proyectos mineros impulsados por empresas, muchas de ellas con domicilio en Canadá, en países como Guyana, Surinam, Perú y Colombia, han sido constatados en un reciente estudio del Instituto Norte Sur ${ }^{19}$.

\section{El marco JURÍdico De loS DEREChOS DE PUEBloS INDÍGENAS EN AMÉrica LATINA}

Con más de 600 pueblos o grupos identificables, y una población estimada entre 40 y 50 millones $^{20}$, los pueblos indígenas representan alrededor del $10 \%$ de la población total de América Latina, convirtiéndose en actores políticos, sociales y culturales en casi todos los Estados que integran la región. Como consecuencia de diversos factores, entre ellos la movilización y demanda de los pueblos indígenas y la democratización política de la región, en las últimas décadas se han verificado procesos de reforma jurídica y política en casi todos los Estados de la región para reconocer la diversidad y derechos de pueblos indígenas.

\section{Reformas jurídicas y pueblos indígenas}

Mediante diversos ciclos $^{21}$ tales derechos han encontrado un creciente reconocimiento en las constituciones políticas (CP) de los Estados. Así, en la década de los

${ }^{16}$ Ver http://www.ilo.org/public/libdoc/ilo/P/09661/09661\%282010-99-1A\%29.pdf [consultada el 20 de abril de 2012].

${ }^{17}$ Ver http://www.cidh.oas.org/medidas/2010.eng.htm [consultada el 21 de abril de 2012].

${ }^{18}$ En agosto de 2011 la CIDH revisó su decisión anterior, limitando su medida cautelar a asegurar a las comunidades indígenas acceso a agua no contaminada. Esta decisión motivó la protesta de más de 200 organizaciones no gubernamentales de la región y de Canadá en carta a la CIDH. Ver http://servindi.org/ pdf/carta_CIDH_21feb2012.pdf[consultada el 17 de marzo de 2012].

19 Weitzner, V., Inclinando la balanza del poder. Logrando que el consentimiento libre, previo e informado funcione, North South Institute, Ottawa, 2011. La investigación también estudia los impactos de las inversiones mineras en territorios de pueblos indígenas en Canadá, cuyos responsables con empresas de este y otros países.

${ }^{20}$ Bello, A. y Rangel, M., Etnicidad, "raza" y equidad en América Latina y el Caribe. CEPAL, Santiago, 2000; y Programa de Naciones Unidas para el Desarrollo (PNUD), Segundo informe sobre desarrollo bumano en Centroamérica y Panamá, PNUD, San José de Costa Rica, 2003.

${ }^{21}$ Para una identificación de los ciclos de reforma constitucional referidos a pueblos indígenas en la región ver: Yrigoyen, R., "El horizonte del constitucionalismo pluralista; del multiculturalismo a la desco- 
ochenta, antecediendo la aprobación del Convenio No 169 de la OIT, Guatemala (1985), Nicaragua (1987) y Brasil (1988) impulsaron reformas que, si bien estaban centradas en el reconocimiento y protección de la plurietnicidad y del derecho a la identidad cultural -tanto individual como colectiva-, establecieron derechos específicos de estos pueblos sobre la tierra y algunas formas de autonomía.

Un segundo ciclo de reformas se desarrolló en los noventa, bajo la influencia del Convenio 169 de la OIT de 1989. Como parte de este ciclo, numerosos Estados introdujeron reformas constitucionales en las que se reconoció a los pueblos indígenas como sujetos colectivos, estableciéndose en ellas derechos políticos de participación, consulta y de autonomía, derechos territoriales relacionados con la tierra, el territorio y los recursos naturales, y derechos de carácter lingüístico y cultural. Por medio de estas reformas, junto con reconocerse la existencia de los indígenas como pueblos diferenciados por las CP de Argentina (1994), Bolivia (1994), Colombia (1991), Ecuador (19994, 1998), México (1992 y 2001), Paraguay (1992) y Venezuela (1999), se enfatizó la naturaleza multicultural o pluricultural de los Estados (Colombia, 1991; México 1992 y 2001; Perú, 1993; Bolivia, 1994; Ecuador, 1998). Varias CP reconocieron los derechos de los pueblos indígenas sobre sus tierras y/o territorios. Así la CP de Argentina (1994) reconoció a los pueblos indígenas derechos de propiedad y posesión comunitaria sobre las tierras que tradicionalmente ocupan. Bolivia, Colombia y Ecuador dispusieron el derecho de estos pueblos a la demarcación, saneamiento y titulación sobre sus territorios comunitarios, protegiéndolos como inalienables y/o indivisibles, así como también reconocieron el derecho de usufructo sobre los recursos naturales existentes en ellos. La protección y la participación de las comunidades indígenas frente a la explotación de recursos naturales en territorios indígenas fue establecida en la CP de Colombia. Igualmente, derechos de autonomía de los pueblos indígenas, por diferentes figuras (resguardos, entidades territoriales indígenas), fueron establecidos en las CP de Colombia (1991) y México (2001).

Las expectativas generadas por estas reformas multiculturales de los noventa, sin embargo, se vieron frustradas. Ello como consecuencia de políticas que, promovidas por el Banco Mundial y el Banco Interamericano de Desarrollo en el contexto del consenso de Washington, incentivaron la apertura de los mercados a la inversión extranjera y la privatización de los servicios sociales básicos, vulnerando los derechos de pueblos indígenas, en particular aquellos referidos al control de sus tierras y recursos. Estas contradicciones determinaron la existencia de lo que el Relator Especial de la ONU para los derechos indígenas identificó como la brecha de implementación de dichas reformas. ${ }^{22}$

lonización”, en Rodríguez, C. (Coord.), El derecho en América Latina. Un mapa para el pensamiento jurídico del siglo XXI, Siglo XXI Ed., México D.F., 2011, pp. 139-160.

${ }^{22}$ Stavenhagen R., Report of the Special Rapporteur on the situation of human rights and fundamental freedoms of indigenous people, Rodolfo Stavenhagen* Addendum, United Nations. E/CN.4/2006/78/Add.5 17 enero de 2006. De acuerdo con el Relator Especial Stavenhagen, dicha brecha de implementación se evidenció en, entre otros aspectos, la distancia entre las disposiciones constitucionales y la norma legal y reglamentaria vigente, la ausencia de mecanismos para hacer exigibles los derechos reconocidos constitucionalmente, la falta de recursos o de voluntad para impulsar políticas públicas para hacerlos efectivos. 
Como consecuencia de los procesos políticos verificados en los países andinos bajo enérgica presión de los movimientos indígenas ${ }^{23}$, Ecuador (2008) y Bolivia (2009) aprobaron, por procesos constituyentes democráticos, nuevas constituciones políticas (CP). Ambas CP, bajo la influencia evidente de la DNUDPI, vienen a deconstruir el concepto de "Estado-Nación", al reconocer la existencia de Estados plurinacionales y proponer la interculturalidad como forma de relación entre los pueblos diferentes que en ellos habitan (Art. 1 CP Ecuador; Art. 1 CP Bolivia). Las mismas CP reconocen a los pueblos indígenas la posesión y propiedad ancestral de sus tierras y territorios ${ }^{24}$, además de establecer en su favor derechos de uso y beneficio de los recursos naturales que se encuentran en sus tierras y territorios ${ }^{25}$. Relacionado con ello, reconocen derechos de consulta previa, libre e informada frente a la exploración y explotación de dichos recursos, y derechos de participación en los beneficios de su explotación. ${ }^{26}$ En el caso de Bolivia, la CP reconoce, además, a las naciones y pueblos indígenas originarios campesinos su libre determinación, en virtud del cual tienen derecho a la autonomía, al autogobierno, a su cultura, al reconocimiento de sus instituciones y a la consolidación de sus entidades territoriales (Art. 2 CP Bolivia). No menos importante es el reconocimiento en la CP de Ecuador del deber del Estado de promover el buen vivir como legado cultural de los pueblos indígenas (samak kawsay en quichua) (Preámbulo CP Ecuador) y de los derechos de la naturaleza o Pacha Mama, incluyendo mecanismos para exigir a la autoridad pública su cumplimiento (Art. $71 \mathrm{CP}$ Ecuador). Estos derechos vienen a cuestionar el paradigma occidental del desarrollo, así como el que solo los individuos o los pueblos sean objeto de protección por parte del dere$\mathrm{cho}^{27}$. Aunque ambas CP son muy recientes, y en los dos contextos se han verificado conflictos relacionados con la legislación para su implementación y los proyectos de

${ }^{23}$ En el primer caso (Bolivia), los pueblos indígenas fueron gravitantes en la conformación del Movimiento al Socialismo (MAS) liderado por Evo Morales, quien el 2005 fue elegido como Presidente de Bolivia, siendo posteriormente reelegido, también con apoyo de los pueblos indígenas, el 2010. En el segundo caso (Ecuador), la Confederación de Nacionalidades Indígenas del Ecuador, y su brazo político, Pachakutik, se convirtieron en actores claves de la política de ese país, participando de la conformación del gobierno de Lucio Gutiérrez, y posteriormente, el 2007, dando su apoyo a la elección de Correa como Presidente de Ecuador. En años recientes, sin embargo, el movimiento indígena de Ecuador se ha distanciado del gobierno de Correa, debido al apoyo gubernamental a la inversión productiva y extractiva en sus territorios.

${ }^{24}$ Entre ellos el derecho a mantener la posesión de tierras y territorios ancestrales y a obtener su adjudicación gratuita (art. 57 CP Ecuador); el dominio ancestral de sus territorios (Art. 2 CP Bolivia): y el derecho a la titulación colectiva de tierras y territorios (TIOC) (Art. 30 CP Bolivia).

${ }^{25}$ Ellos incluyen derechos de usufructo, conservación y administración de recursos naturales (art. 57 CP Ecuador); y el uso y aprovechamiento exclusivo de los recursos naturales renovables y la participación en los beneficios de la explotación de los recursos naturales en sus territorios (Art. 30 CP Bolivia)

${ }^{26}$ Tales derechos incluyen la consulta previa, libre e informada frente a la exploración y explotación de dichos recursos, y la participación en los beneficios de su explotación (Art. 57 CP Ecuador). En el caso de Bolivia, la consulta frente a la explotación de los recursos naturales no renovables en el territorio que habitan debe ser previa, obligatoria, realizada por el Estado, de buena fe y concertada (Art. 30 CP Bolivia).

${ }^{27}$ Zaffaroni, E. R., "La naturaleza como persona: Pachamama y Gaia”, en Calizaya, A. y Zaffaroni, E. R., Nuevo constitucionalismo ambiental (Perspectivas desde lo plurinacional comunitario). Latinas Editores, Uru uru Marka, 2009, pp. 35-62. 
inversión extractivos o de infraestructura en territorios indígenas ${ }^{28}$, sin duda estas establecen un nuevo escenario para la protección de los derechos políticos y territoriales de pueblos indígenas en la región.

En la misma línea cabe hacer una referencia al desarrollo de los derechos de consulta de pueblos indígenas frente a medidas administrativas, muchas de ellas relacionadas con proyectos de inversión que afectan sus tierras y territorios. En materia de desarrollo normativo de este derecho destaca el caso de Perú, cuyo Congreso Nacional aprobó el

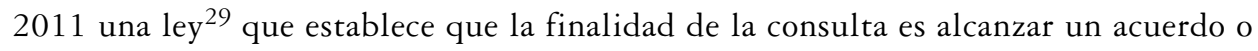
consentimiento entre el Estado y los pueblos originarios frente a medidas administrativas y legislativas que les afecten directamente. ${ }^{30}$ En materia jurisprudencial destaca el caso de Colombia, cuya Corte Constitucional ha fallado 18 tutelas a favor de los pueblos indígenas entre 1993 y 2006 como consecuencia de violación del derecho al territorio por el desarrollo en ellos de proyectos de inversión sin procesos de consulta $\operatorname{adecuados}^{31}$. En dicha jurisprudencia la Corte Constitucional colombiana ha establecido como criterio que cuando se trata de planes de desarrollo o de inversión a gran escala, que tengan mayor impacto en los territorios indígenas, el Estado no debe solo consultar sino también obtener el consentimiento previo, libre e informado (CLPI) de estos pueblos ${ }^{32}$.

${ }^{28}$ El ejemplo más claro es el del conflicto generado en Bolivia con los planes del gobierno de Evo Morales de construir una carretera que atraviesa el territorio indígena protegido de TIPNIS, el que ha sido sólidamente resistido por los pueblos indígenas de ese país.

${ }^{29}$ Texto sustitutorio de los proyectos de Ley $\mathrm{N}^{\text {os }}$ 6-2011/CR,29-2011/CR.47-2011/CR 49-2011/ y Cr 89-2011 Relativos a ley de derecho a la consulta previa a los pueblos indígenas u originarios reconocidos en el Convenio $\mathrm{N}^{\circ} 169$ de la OIT.

${ }^{30}$ Entre los principios que rigen la consulta se identifican interculturalidad, oportunidad, buena fe, flexibilidad, plazo razonable, ausencia de coacción, información oportuna (art. 4). Los acuerdos logrados en la consulta son exigibles, en caso de incumplimiento, en vía administrativa y judicial. La ley dispone que de acuerdo entre el Estado y los pueblos indígenas como resultado del proceso de consulta es de carácter obligatorio para ambas partes. "En caso que no se alcance un acuerdo, corresponde a las entidades estatales adoptar todas las medidas que resulten necesarias para garantizar los derechos colectivos de los pueblos" (Art. 15 Ley Consulta previa a pueblos indígenas Perú, 2011).

${ }^{31}$ Anaya, J., La situación de los pueblos indígenas en Colombia: Seguimiento a las recomendaciones hechas por el Relator Especial anterior. Naciones Unidas, A/HRC/15/34 8 de enero de 2010.

${ }^{32}$ Ver Corte Constitucional de Colombia, Sentencia T-769/09 recaída en el caso Álvaro Bailarín y otros por actividades exploratorias y extractivas de recursos minerales de Muriel Mining, de capitales estadounidenses, en territorio emberá, que no fueron consultadas. Ver además Sentencia número T-129, de 3 de marzo del 2011, que ordena realizar en forma debida la consulta buscando obtener el consentimiento previo, libre e informado en torno a tres proyectos que afectaban al pueblo indígena embera katío: la construcción de una carretera, la interconexión eléctrica binacional Colombia-Panamá y una concesión minera. La sentencia ordena también detener la ejecución de estos proyectos en tanto no se realicen las consultas correspondientes a los pueblos indígenas afectados. 


\section{Implicancias de la recepción en América Latina del derecho internacional de los derechos bumanos aplicables a los pueblos indígenas}

A lo anterior se suman las implicancias que la recepción del derecho internacional de los derechos humanos aplicables a los pueblos indígenas está teniendo en los Estados de la región. Tales implicancias son consecuencia, por un lado, de la ratificación por parte de los Estados de América Latina del Convenio $\mathrm{N}^{\circ} 169$ de la OIT ${ }^{33}$, el que reconoce a los pueblos indígenas un conjunto de derechos políticos (participación, consulta y autonomía y autogestión) así como de derechos sobre sus tierras, territorios y recursos naturales. De relevancia en el contexto de la presión de proyectos extractivos que hoy proliferan en los territorios indígenas resulta el deber de consulta del Estado frente a medidas administrativas y legislativas susceptibles de afectarles directamente, consulta que, de acuerdo con el Convenio, debe ser realizada de buena fe por las organizaciones representativas de los pueblos indígenas, y estar orientadas a lograr el acuerdo o consentimiento frente a ellas (artículo 6). Igualmente significativo es el derecho de los pueblos indígenas a definir sus prioridades en materia de desarrollo (artículo 7). A ello se agrega la adhesión que han hecho los Estados de la región a la DNUDPI ${ }^{34}$, la que en muchas materias va más allá del Convenio 169. Ello, por ejemplo, al disponer que los Estados tienen la obligación no solo de consultar sino de recabar el consentimiento libre, previo e informado de los pueblos indígenas antes de adoptar decisiones que les afectan. Entre las decisiones que de acuerdo con la DNUDPI requieren del consentimiento de estos pueblos, se encuentran aquellas referidas a su traslado desde sus tierras y territorios (artículo 10), aquellas de carácter legislativo y administrativas que les afecten (artículo 19), y la aprobación de proyectos que afecten sus tierras o territorios y otros recursos, particularmente aquellos relacionados con la explotación o utilización de recursos minerales o hídricos (artículo 32.2). Ello es consecuencia del reconocimiento explícito que la misma DNUDPI hace a estos pueblos del derecho a la libre determinación (artículo 3), así como del derecho a la autonomía en asuntos internos y locales (artículo 4). Aunque en muchos casos se trate de una adhesión formal, la DNUDPI ha comenzado a ser considerada por algunos Estados (Bolivia) en su legislación interna, así como por los tribunales de justicia y cortes constitucionales en diversos contextos (Belice, Colombia y Chile, entre otros) ${ }^{35}$.

A la protección de estos derechos en la región ha contribuido de manera fundamental, además, la jurisprudencia de la Corte Interamericana de Derechos Humanos (Corte IDH) en sus decisiones frente a las denuncias que los pueblos indígenas han presentado por la

33 Quince del total de veintidós a nivel global.

${ }^{34}$ Colombia se abstuvo de dar su aprobación a esta Declaración en la votación de la Asamblea General de la ONU el 2007. El 2009, sin embargo, adhirió a ella.

${ }^{35}$ Las implicancias de la DNUDPI han sido significativas. Un ejemplo de ello es el que la Corporación Financiera Internacional, miembro del Grupo del Banco Mundial, adoptó en su marco de sostenibilidad el principio del CLPI para aquellos proyectos de inversión con potenciales impactos adversos sobre los pueblos indígenas. Ver http://www.diplomaciaindigena.org/2011/05/eeuu-corporacion-financiera-internacionaldel-banco-mundial-adopta-principio-de-consentimiento-libre-previo-e-informado-para-ppii/ [consultada el 15 de abril de 2012]. 
violación de derechos humanos amparados en las disposiciones de la Declaración Americana de los Derechos y Deberes del Hombre (Declaración) y de la Convención Americana sobre Derechos Humanos (Convención) ${ }^{36}$. Uno de los ámbitos en que la jurisprudencia de la Corte IDH ha sido más abundante es el que dice relación con el reconocimiento y protección de los derechos de propiedad ancestral de los pueblos indígenas sobre sus tierras, territorios y recursos naturales. Ello al hacer una interpretación evolutiva del derecho de propiedad privada (Art. XXIII de la Declaración; Art. 21 de la Convención). Así en el caso Awas Tingni vs. Nicaragua (2001) la Corte reconoció a la luz del artículo 21 de la Convención Americana de Derechos Humanos la propiedad comunal de los pueblos indígenas sobre la tierra ${ }^{37}$. Asimismo, reconoció la validez de la posesión de la tierra basada en la costumbre indígena, aun a falta de título, como fundamento de su propiedad sobre ellas, y la necesidad de que la estrecha relación que los indígenas tienen con sus tierras sea reconocida y comprendida como la base fundamental de sus culturas, su vida espiritual, su integridad y su supervivencia económica ${ }^{38}$.

En años posteriores la Corte IDH ratificó su interpretación sobre la materia al reconocer los derechos de carácter comunal sobre las tierras ancestrales a las comunidades de Yakye Axa y Sawhoyamaka en Paraguay ${ }^{39}$. Aun cuando en estos casos la propiedad legal era detentada por privados, la Corte IDH estableció la necesidad de restringir la propiedad privada de los particulares, siempre que se pagase una justa indemnización a los perjudicados de conformidad con el artículo 21.2 de la Convención ${ }^{40}$. Igualmente relevante, en su sentencia en el caso Sawhoyamaxa vs. Paraguay la Corte IDH sostuvo que el derecho a la reivindicación de las tierras de propiedad ancestral reclamadas por estos pueblos no se extinguía mientras estas mantuviesen su relación con ellas, fuese esta material o espiritual ${ }^{41}$.

De especial relevancia en relación con los proyectos de inversión en tierras y territorios indígenas es la decisión adoptada por la Corte IDH el 2007, caso del pueblo Saramaka vs. Surinam. En este caso la Corte, junto con establecer que los pueblos indígenas tienen derecho a usar y gozar de los recursos naturales que se encuentren en las tierras ancestrales que tradicionalmente ocupan y que son necesarios para la continuidad de su estilo de vida, se pronunció sobre los planes de desarrollo o inversión de gran escala que provocan impacto mayor en los territorios de este pueblo. La Corte IDH sostiene al respecto que los Estados tienen la obligación no solo de consultar a estos pueblos de

\footnotetext{
${ }^{36}$ El Sistema Interamericano de Derechos Humanos no cuenta con un instrumento específico referido a los pueblos indígenas y sus derechos. Un proyecto de la Declaración Americana de Derechos de Pueblos Indígenas se debate en el seno de la Comisión IDH desde mediados de los noventa, pero aún no ha sido aprobado.

${ }^{37}$ Corte IDH, Sentencia en caso Awas Tingni vs. Nicaragua, 2001, para. 148-149.

${ }^{38}$ Ibid, para. 151

${ }^{39}$ Corte IDH, Sentencia en caso Yakye Axa vs. Paraguay, 2005; Corte IDH, Sentencia Sawhoyamaka vs. Paraguay, 2006.

${ }^{40}$ Corte IDH, Sentencia en caso Yakye Axa vs. Paraguay, 2005, para. 149.

${ }^{41}$ Así la Corte sostiene que "mientras que esta relación exista, el derecho de reivindicación permanecerá vigente”. Corte IDH, Sentencia caso Sawhoyamaxa vs. Paraguay, 2006, para. 131.
} 
manera apropiada, sino también de obtener, como lo señala la DNUDPI, su consentimiento libre, previo e informado, según sus costumbres y tradiciones ${ }^{42}$. Al amparo del artículo 21.2 de la Convención la Corte IDH dispuso además que este pueblo tiene derecho a participar, en forma razonable, de los beneficios derivados de la restricción o privación del derecho al uso o goce de sus tierras y de los recursos naturales necesarios para su supervivencia ${ }^{43}$.

Cabe señalar que la jurisprudencia de la Corte IDH ha tenido importante recepción por los tribunales de justicia y órganos de control constitucional de los Estados de la región ${ }^{44}$. Todo ello genera un nuevo escenario referido a los derechos de pueblos indígenas en la región, el que no puede ser ignorado por los Estados de América Latina, así como tampoco por otros Estados, como Canadá, cuando intentan expandir sus actividades comerciales en los territorios de pueblos indígenas.

\section{LOS DERECHOS DE LOS PUEBLOS INDÍGENAS EN CANADÁ: AVANCES Y TENSIONES EN EL CONTEXTO DE UNA ECONOMÍA EXTRACTIVA}

Con una población de 1,3 millones, que representa cerca del $5 \%$ de la población total de Canadá, los pueblos indígenas de este país -52, agrupados en 614 comunidades- ${ }^{45}$ también han logrado en las últimas décadas, al menos en el plano formal, avances significativos en el reconocimiento de sus derechos colectivos. En efecto, luego de un largo período de asimilación forzada y desposeimiento de sus tierras y recursos naturales por los colonizadores ingleses y franceses, a contar de la década de los setenta se han impulsado procesos de reconocimiento de estos pueblos y de sus derechos, consecuencia directa de sus procesos organizativos y de su movilización. Ellos se expresan en la jurisprudencia de la Corte Suprema de Canadá, la que ha reconocido el "título aborigen" de sus tierras no cedidas por tratados (caso Calder v. British Columbia (1973)). También

${ }^{42}$ En relación con el consentimiento, la Corte IDH sostiene: “Asimismo, la Corte considera que, cuando se trate de planes de desarrollo o de inversión a gran escala que tendrían un mayor impacto dentro del territorio Saramaka, el Estado tiene la obligación no solo de consultar a los Saramakas, sino también debe obtener el consentimiento libre, informado y previo de estos, según sus costumbres y tradiciones" (Corte IDH, Sentencia caso Saramaka vs. Surinam, 2008, para. 135).

43 Al respecto la Corte IDH concluye: "En este contexto, de conformidad con el artículo 21.2 de la Convención, se puede entender la participación en los beneficios como una forma de indemnización razonable y en equidad que deriva de la explotación de las tierras y recursos naturales necesarios para la supervivencia del pueblo Saramaka" (Corte IDH, Sentencia caso Saramaka vs. Surinam, 2008, para. 141).

${ }^{44}$ Ello tomando en cuenta que, como la misma Corte IDH ha señalado, ella es el órgano encargado de interpretar el sentido y alcance de los tratados internacionales de derechos humanos.

${ }^{45}$ Stavenhagen R., Report of the Special Rapporteur on the situation of human rights and fundamental freedoms of indigenous people, Rodolfo Stavenhagen. Addendum MISSION TO CANADA, E/CN.4/2005/88/ Add.3, 2004 
en el reconocimiento de su existencia y derechos, incluyendo aquellos emanados de tratados, en el Acta Constitucional de $1982^{46}$, así como de su derecho al autogobierno ${ }^{47}$.

Lo anterior ha llevado a la revisión de las políticas públicas que conciernen a estos pueblos, y al impulso de políticas de restitución de tierras reconocidas mediante tratados antiguamente celebrados con los colonizadores. También ha dado lugar a la negociación de tratados modernos, mediante los cuales el gobierno de Canadá ha reconocido a diversos pueblos indígenas derechos exclusivos y/o compartidos sobre sus tierras y recursos naturales de propiedad ancestral, incluyendo en algunos casos derechos al subsuelo ${ }^{48}$. Además de ello, estos tratados han incluido derechos de pesca y caza, participación en la administración de tierras y recursos naturales sobre espacios territoriales que permanecen en poder de Canadá, compensación financiera, participación en las utilidades de actividades económicas en sus territorios, y apoyo al desarrollo. Entre 1973 y a la fecha 25 tratados o acuerdos comprensivos por reclamaciones de tierras (comprehensive land claim agreements) han sido suscritos por Canadá, y en algunos casos por las provincias, cubriendo alrededor del $40 \%$ del territorio canadiense. A contar del tratado celebrado con los Nisga'a el 2000, mecanismos de autogobierno indígena en materias políticas y económicas, incluyendo la gobernanza sobre los recursos naturales, han sido establecidos. Los mismos tratados han resultado en la transferencia de importantes recursos económicos a los pueblos indígenas como compensación por sus derechos sobre sus restantes tierras, derechos que dichos tratados, hasta hace poco, han declarado formalmente "extinguidos", cuestión cuestionada por los pueblos indígenas y por instancias internacionales ${ }^{49}$. No obstante lo anterior subsisten muchas reclamaciones indígenas sobre vastos territorios sin ser resueltas, en particular en Columbia Británica y los territorios al norte del paralelo

\footnotetext{
${ }^{46}$ La sección 35 de la Constitución canadiense (Acta Constitucional) de 1982 reconoce a los pueblos aborígenes (aboriginal peoples), denominación que integra las categorías de "indios, métis e inuit". Los derechos de tratado incluyen tanto aquellos existentes como los que sean adquiridos mediante acuerdos de reclamación de tierras.

47 El gobierno canadiense manifestó en 1995 su disposición de llegar a acuerdos con los distintos pueblos indígenas posibilitando el ejercicio por parte de ellos de poderes legislativos y administrativos en una amplia gama de materias internas a sus comunidades. Los únicos poderes que han sido excluidos de la negociación de acuerdo con esta política son aquellos que dicen relación con la soberanía canadiense, la defensa, las relaciones externas, la política monetaria, el derecho criminal sustantivo, la protección de la salud entre otras. Ver Government of Canada (Minister of Indian Affairs and Northern Development), Aboriginal Self-Government. The Government of Canada's Approach to Implementation of the Inherent Right and the Negotiation of Aboriginal Self-Government, DIAND, Ottawa, 1995.

${ }^{48}$ Es el caso de los derechos sobre recursos del subsuelo reconocidos por el gobierno de Canadá mediante tratados modernos a los Gwich'in (1992), a los Sahtu Dene y Metis (1993), a los Inuit (1993) y a los Nisga'a (2000).

${ }^{49}$ Stavenhagen (2004), op. cit.
} 
$60^{\circ 50}$. Igualmente, los pueblos indígenas cuestionan la falta de implementación de los tratados modernos hasta ahora suscritos ${ }^{51}$.

A pesar del evidente progreso que los tratados modernos y las políticas públicas impulsadas en las últimas décadas han significado para los pueblos indígenas y sus derechos, los procesos de desposeimiento de los pueblos indígenas han seguido adelante en Canadá. Ello en particular en el contexto del fortalecimiento de la actividad extractiva como pilar central de la economía canadiense, actividad que afecta de manera significativa a los territorios reconocidos o reivindicados y en negociación con los pueblos indígenas. ${ }^{52}$

Cabe referirse por ello al marco jurídico canadiense relativo a la extracción de recursos naturales cuando este afecta a los pueblos indígenas y su título aborigen, así como a las políticas públicas y prácticas empresariales referidas a la extracción de recursos naturales en tierras y territorios indígenas en Canadá.

El reconocimiento de los derechos indígenas y de tratado en el Acta Constitucional de 1982 llevó a los tribunales a establecer el deber de Canadá (Crown), basado en su obligación fiduciaria con los pueblos indígenas, de consultar y de acomodar con ellos sus intereses en una serie de materias, incluyendo en algunos casos proyectos extractivos en sus tierras ancestrales. Así en R.v Sparrow (1990) la Corte Suprema de Canadá estableció que cuando los derechos indígenas eran afectados el grupo involucrado debía ser consultado por la Corona en relación con medidas de conservación. También estableció que cuando operaba una expropiación el grupo debía ser compensado. En el caso Delgamuukw v. British Columbia (1997), la misma Corte, junto con confirmar su derecho al título aborigen sobre tierras no cedidas por tratados, estableció que la Corona tenía la obligación no solo de consultar, sino también de acomodar sus intereses en el contexto de la afectación del título aborigen. En el mismo caso sostuvo que la consulta debía realizarse en buena fe, con la intención de responder sustancialmente a las preocupaciones de los pueblos indígenas cuyas tierras eran afectadas, lo que tiene implicancias más

${ }^{50}$ De acuerdo con Stavenhagen (2004, op cit.), al 2004 existían 42 mesas de negociación sobre tierras indígenas con más de 437 comunidades. En la provincia de Columbia Británica, por ejemplo, solo cinco naciones de un total de 60 partícipes del British Columbia Treaty Commission habían concluido a inicios del 2012 acuerdos sobre reclamaciones de tierras, en tanto el resto se encontraba en procesos de negociación. Ver http://www.bctreaty.net/files/pdf_documents/update_january-2012.pdf [consultada el 13 de abril de 2012].

51 A juicio de los pueblos indígenas, ello ha determinado que tales tratados no hayan cambiado sustancialmente las condiciones de vida de las comunidades, ni alterado la relación colonial con el Estado canadiense. Ver Land Claims Agreements Coalition, Submission to the Standing Committee on Aboriginal Affairs and Northern Development May 12, 2009 “A Legacy of Colonialism and Paternalism”. Disponible en http://www.landclaimscoalition.ca/pdf/090504-LCAC_Submission_to_AANO-Final.pdf [consultado el 3 de abril de 2012].

52 Como señalara el Primer Ministro Harper en su intervención en la Cumbre de las Américas en Colombia, la industria extractiva de recursos naturales es hoy central para la economía de Canadá. Aunque una parte no menor de ella se desarrolla, como hemos visto en el caso de América Latina, fuera de Canadá, con un valor estimado de 200 billones de dólares, ella constituye hoy más de un quinto de las exportaciones canadienses. Ver Harper, S. "Looking to the future, we see increased Canadian mining investment throughout the Americas, something that will be good for our mutual prosperity and is therefore a priority of our Government.", Statement by the Prime Minister of Canada in Cartagena, Colombia. Disponible enhttp://www. pm.gc.ca/eng/media.asp? category=3\&featureId =6\&pageId=26\&id = 4742 [consultada el 28 de abril de 2012]. 
profundas que una mera consulta ${ }^{53}$. En fallos posteriores la Corte Suprema ha definido con mayor precisión el alcance de las obligaciones de la Corona. Así, en el Haida Nation vs. British Columbia (2004) sostuvo que la consulta debía ser implementada cuando la Corona tuviese conocimiento de la potencial existencia de un derecho o título aborigen, y contemplase una conducta que pudiese afectarle adversamente. También cuando pudiese afectar adversamente derechos de algún tratado histórico (Mikisew Cree First Nation vs. Canada (2005). En el caso Haida (2004), además, la Corte enfatizó que la consulta no otorga a los pueblos indígenas un derecho de veto, y definió la acomodación como un proceso orientado a lograr acuerdo en un intento de armonizar los intereses en conflicto. Finalmente en el caso Taku River Tinglit vs. British Columbia (2004) la Corte Suprema agregó que en casos de afectación del título aborigen era necesario adoptar medidas para evitar un impacto, minimizarlo o mitigarlo, y como alternativa compensarlo. La misma Corte sostuvo que el espectro de la consulta y de la acomodación dependían del nivel de riesgo de una iniciativa en los derechos constitucionales indígenas. Así, mientras mayor fuese el riesgo, más necesidad habría de desarrollar estos procesos.

Cabe señalar que la legislación sobre recursos naturales también ha establecido, en algunos casos, la necesidad de la consulta con pueblos indígenas, así como también acuerdos de beneficio frente a ciertas situaciones. Así, por ejemplo, a nivel federal el Acta de Operaciones de Petróleo y Gas (Sección 5 (2)) requiere de la aprobación por parte del Ministerio de Asuntos Indígenas de un plan de beneficios por parte del proponente -como empleo, provisión de servicios u otros a favor de grupos desventajados- antes de que una actividad sea autorizada. Asimismo, el Acta de Petróleo de Canadá dispone que las empresas deben establecer planes o beneficios antes del inicio de una faena en tierras de propiedad de la Corona. En el territorio de Yukón, por último, la Ley sobre Petróleo y Gas se refiere explícitamente a la necesidad de contar con el consentimiento de los afectados antes del inicio de actividades de exploración y extracción de estos recursos naturales ${ }^{54}$.

Igualmente relevante, algunos tratados modernos establecen la necesidad de contar con procesos de consulta y acuerdos de impacto-beneficios (IBA en su sigla en inglés) con los pueblos indígenas antes del desarrollo de proyectos de inversión que afecten sus tierras y recursos. Así por ejemplo, el tratado de Nunavut de 1993 estableció que ningún proyecto de inversión mayor puede comenzar sin un acuerdo de impacto-beneficio (Art. 26). El acuerdo de Inuvialuit en el North West Territories (NWT) de 1984 requiere de la suscripción de acuerdos relativos al acceso y uso de la tierra y a la participación en los beneficios. El acuerdo de Gwich'in y Sahtu de 1993, a su vez, incluye la necesidad

${ }^{53}$ De acuerdo con algunos analistas, esta decisión determina que en ciertos casos la consulta implica la obtención del consentimiento indígena. Viviane Weitzner, comunicación personal con el autor, septiembre de 2012 .

${ }^{54}$ Weitzner, V., op. cit. La jurisdicción de las provincias y de los territorios sobre los recursos naturales genera muchos conflictos en torno a la responsabilidad en los procesos de consulta y consentimiento indígena, así como en el otorgamiento de concesiones sobre los mismos, lo que afecta negativamente a los pueblos indígenas. Viviane Weitzner, comunicación personal con el autor, septiembre de 2012. 
de establecer IBA tratándose de proyectos que afectan el suelo y subsuelo de propiedad de la Corona. Tratándose de recursos del subsuelo se requiere de consulta, en la que se puede incluir la participación en los beneficios. Finalmente, el acuerdo Tlicho (2003) requiere de negociación -aunque no necesariamente de finalización- de un IBA en relación con grandes proyectos mineros, como consecuencia de lo que los Tlicho han recibido en los últimos años royalties de las compañías mineras 55 .

El desarrollo jurisprudencial antes referido, así como la crítica de los pueblos indígenas a la decisión del gobierno canadiense de no votar favorablemente la DNUDPI el 2007, Declaración que, como se señalara, reconoce el derecho de estos pueblos al consentimiento, libre, previo e informado (CLPI) frente a, entre otros, los proyectos de utilización o explotación de recursos naturales en sus tierras y territorios, han llevado en los últimos años al gobierno canadiense a establecer directrices sobre el deber de consulta con los pueblos indígenas. De acuerdo con estas directrices, la consulta es entendida como una responsabilidad de los órganos del Estado que debe desarrollarse cada vez que una actividad propuesta por el gobierno de Canadá pueda impactar adversamente los derechos o intereses relacionados de los pueblos indígenas. Las mismas directrices establecen, entre otros criterios, que esta debe ser temprana, rápida, transparente, accesible, basada en la buena fe, el respeto y la responsabilidad, y que ella implica el deber de acomodar intereses con los pueblos indígenas, y no solo de consultarlos ${ }^{56}$. Tales directrices, sin embargo, han sido cuestionadas por la Asamblea de las Primeras Naciones, así como otras organizaciones indígenas. Así han sostenido que ellas no han sido consultadas con los pueblos indígenas, y que tampoco son consistentes con el derecho al CLPI establecido por la DNUDPI, Declaración que Canadá suscribió el 2010, aunque con observaciones que limitan su alcance a su compatibilidad con el derecho interno ${ }^{57}$.

Aunque no son consideradas como legalmente obligatorios, la jurisprudencia de las cortes canadienses sobre el deber de consulta y la acomodación de intereses con pueblos indígenas antes referida, ha llevado a las empresas a impulsar negociaciones relativas a los impactos y a los beneficios de sus actividades en tierras y territorios de pueblos indígenas. Ello ha derivado en la práctica de los Acuerdos de Impacto-Beneficio (IBA en su sigla en inglés), la que se ha establecido como práctica habitual en proyectos de inversión que afectan a los pueblos indígenas. Los IBA son entendidos como acuerdos bilaterales confidenciales generalmente negociados entre compañías mineras y comunidades indígenas para abordar los impactos tanto socioeconómicos como biofísicos

55 Gibson, G. y O'Faircheallaigh, C. IBA Community Toolkit. Negotiation and Implementation of Impact benefit Agreements. Walter \& Duncan Gordon Foundation, Toronto, 2010.

56 Government of Canada, Aboriginal Consultation and Accommodation, Updated Guidelines for Federal Officials to Fulfil the Duty to Consult. Minister of the Department of Indian Affairs and Northern Development, Ottawa, 2011.

57 Joint Statement by the Assembly of First Nations et al., Permanent Forum on Indigenous Issues, tenth Session. Nueva York, 16 a 27 de mayo de 2011, disponible en http://www.afn.ca/index.php/en/newsmedia/current-issues/permanent-forum-on-indigenous-issues-free-prior-and-informed-consent [consultado el 25 de abril de 2012]. 
que pueden emanar de un proyecto minero ${ }^{58}$. Una de las materias más frecuentemente abordadas en estos acuerdos son los beneficios financieros provistos por las empresas a las comunidades indígenas impactadas por sus actividades. Ello en razón de la necesidad de compensar los daños socioambientales y culturales que estas actividades provocan en ellas, así como en razón de que en muchos casos los pueblos indígenas son los propietarios de la tierras, y en algunos casos de los recursos del subsuelo, en los que estas se desarrollan.

Algunos ejemplos de estos acuerdos incluyen el que los inuit de Nunavik y la compañía minera Raglan suscribieron en 1995 antes del desarrollo de la mina Raglan que impactaba las comunidades indígenas. Mediante este acuerdo, el primero de este tipo sin participación del gobierno de Canadá, la compañía se comprometió a proveer a las comunidades el 4,5\% de las ganancias de la mina una vez que hubiese recuperado su inversión inicial. Por este concepto los inuit, por medio de la Corporación Makivik y las dos comunidades directamente afectadas, habían recibido al 2008 65,4 millones de dólares. Al 2006 el empleo de los inuit alcanzaba entre el 15 y el $18 \%$ del total del empleo de la mina. ${ }^{59}$

Otro caso es el de los IBA suscritos por los innu y los inuit con la minera International Nickel Company (INCO) ${ }^{60}$ para el desarrollo del proyecto minero Voisey's Bay, en Labrador. Las negociaciones datan de la década del noventa, cuando estos pueblos negociaban con el gobierno un tratado moderno. En los dos acuerdos suscritos, uno para cada pueblo, la compañía se comprometió a proveer educación, capacitación y empleos para la comunidad, así como a pagar a los innu un royalty del $5 \%$ y del $3 \%$ a los inuit. De acuerdo con la información disponible, como consecuencia de los acuerdos entre el 2003 y el 2007 los innu han recibido CAD \$ 4 millones por concepto de participación en los beneficios de la actividad de la minera. En cuanto a los empleos, el $24 \%$ de los puestos en la mina son desempeñados por los innu e inuit ${ }^{61}$. Otro caso a destacar es el

58 Fidler, Courtney y Michael Hitch, "Impact Benefit Agreements: A contentious issue for environmental and aboriginal justice”. En Environmental Journal 35 (2) 2007,49-69. Disponible en http://cbern. sharpschool.com/kr/One.aspx? objectId = 10486948\&contextId = 677979\&lastCat = 10486919 [consultada el 14 de abril de 2012]. Aunque las materias sobre las que estos tratan varían en cada caso, entre los temas que generalmente se abordan en ellos se encuentran el acceso indígena a los lugares de las faenas; la capacitación y el empleo, así como las condiciones laborales de los integrantes de las comunidades; las oportunidades comerciales para la comunidad en la provisión de servicios vinculados a la actividad propuesta; la protección ambiental del territorio; los beneficios financieros para las comunidades; los mecanismos para la implementación de los acuerdos y la resolución de los conflictos a que den lugar (Gibson, G. y O'Faircheallaigh, C. op. cit.).

${ }^{59}$ Canadian Centre for Community Renewal et al., Aboriginal Minig Guide, 2009. Disponible en http:// www.miningguide.ca/sites/all/files/AMG_CaseStudy2_Raglan_online.pdf [consultada el 3 de abril de 2012]

${ }^{60}$ INCO, compañía de capitales canadienses, fue adquirida el 2006 por la compañía minera brasileña VALE, pasando a convertirse en Vale INCO.

${ }^{61}$ Canadian Centre for Community Renewal et al., op. cit.; Pain, I. y Paddon, T. Negotiating Agreements: Indigenous And Company Experiences: Presentation Of The Voisey's Bay Case Study From Canada, International Seminar on Natural Resource Companies, Indigenous Peoples and Human Rights: Setting a Framework for Consultation, benefit Sharing and Dispute Resolution. Moscu, Diciembre de 2008. Disponible en http://www. ohchr.org/Documents/Issues/IPeoples/Seminars/Vale_Inco_Canada_Voiseys_Bay_case_Moscow_Workshop. pdf [consultada el 4 de abril de 2012]. 
de los Tlicho, quienes basados en el tratado que suscribieran con la Corona el 2003, han de recibir el 10,4\% de los primeros dos millones de dólares de los royalties percibidos por el gobierno, y el 2,08\% de cualquier otro royalty adicional existente ${ }^{62}$.

Aunque esta práctica de las empresas que invierten en territorios indígenas en Canadá parece novedosa, y contrasta marcadamente con las prácticas de empresas canadienses en territorios indígenas en América Latina antes referidas, en muchos casos las empresas extractivas siguen actuando en territorios indígenas en este país en abierta violación de los derechos reconocidos a estos pueblos por el derecho internacional. En efecto, en muchos casos las exploraciones y explotación de recursos naturales en tierras indígenas siguen realizándose sin procesos de consulta adecuados, sin requerir el CLPI de pueblos indígenas, y sin compensación por los daños provocados. Los procesos de consulta impulsados con estos pueblos, lejos de ser determinantes en relación con la materialización o no de una iniciativa, se verifican luego de que la decisión sobre ellos ha sido adoptada por la autoridad. Por lo mismo tienden a centrarse en la mitigación de los impactos que estos proyectos generan en los pueblos indígenas. ${ }^{63}$

De acuerdo con la información disponible, además, las provincias no impulsan procesos de consulta y acomodación con los pueblos indígenas en la fase de exploración de proyectos extractivos. Como consecuencia de ello una docena de pueblos indígenas a lo largo de Canadá han denunciado la realización de exploraciones en contra de su voluntad en sus tierras. Aun cuando las cortes han obligado en varios casos al desarrollo de procesos de consulta previa, muchos pueblos indígenas no pueden recurrir a estos procedimientos a causa de los elevados costos asociados a la litigación ${ }^{64}$. En cuanto a la

${ }^{62}$ Gibson, G. y O’Faircheallaigh, C., op. cit.

63 Como señala Amnistía Internacional en su reciente informe al Comité para la Eliminación de la Discriminación Racial en relación con las prácticas hoy dominantes de los proyectos extractivos en tierras indígenas en Canadá:

Large scale resource development on Indigenous lands, such as mining, oil sands extractions, oil and gas development and clear-cut logging, presents an inherent challenge to the integrity of Indigenous peoples' use of the land. Under international human rights standards, Indigenous peoples have a right to free, prior and informed consent; i.e. to make their own informed decision about whether such development should proceed. In practice, consultation with Indigenous peoples typically occurs after the decision to prioritize extractive development over other land uses has already taken place. Consequently consultation tends to be confined to the mitigation of adverse project impacts rather than to the more fundamental question of whether the project should proceed or whether the land should be protected for other uses. Furthermore, governments in Canada typically rely on project proponents, or on regulatory agencies with limited mandates in respect to Indigenous rights, to carry out such consultations. Indigenous peoples who determine that a proposed project is incompatible with their use of the land typically have little recourse to prevent it going ahead, short of a lengthy legal battle that most are unable to afford. (Amnesty International, Canada. Briefing to the UN Committee on the Elimination of Racial Discrimination, 80th Session, Febrero de 2012. Disponible en http://www2.ohchr.org/english/bodies/cerd/docs/ngos/AI_CANADA_CERD80.pdf [consultada el 21 de abril de 2012]).

${ }^{64}$ Mining Watch Canada, Fundamental Improvements Needed; The Mining Sector and Indigenous Rights in Canada. Submisssion on Canada's 19tth and 20th Periodic Reports to The Committee on the Elimination of Racial Discrimination, enero de 2012. Disponible en http://www2.ohchr.org/english/bodies/ cerd/docs/ngos/MW_Canada80.pdf [consultada el 20 de abril de 2012]. 
fase de explotación, la legislación y políticas de los gobiernos provinciales determinan que ella se realice sin procesos orientados a obtener el CLPI de los pueblos indígenas de conformidad con las normas internacionales. Ello ha obligado a muchos pueblos indígenas en Ontario, y Columbia Británica, entre otras provincias, a recurrir a las cortes, como único resorte para impedir su materialización. Ejemplos recientes de los esfuerzos de los gobiernos (federal y provinciales) de imponer grandes proyectos de inversión en tierras indígenas son los ductos propuestos para el transporte de petróleo desde el norte por Canadá (TransCanada Pipeline) y hacia el Pacífico (Northern Getaway Pipeline). Aunque la materialización de estos megaproyectos es aún incierta, la oposición abierta expresada a ellos por los pueblos indígenas (Lubicon Cree y las primeras naciones de Columbia Británica) no ha sido un factor que haya persuadido a estos gobiernos de no seguir adelante con sus planes ${ }^{65}$.

En cuanto a los IBA, si bien estos se han transformado en un mecanismo relevante para establecer mejores relaciones entre las empresas extractivas y los pueblos indígenas, particularmente referidas a compartir los beneficios de sus proyectos, la experiencia aun muy reciente de su implementación demuestra que estos son muchas veces impuestos aún cuando las comunidades, o parte de ellas, se oponga a un proyecto de inversión ${ }^{66}$. Por otro lado, estos no siempre logran mejorar las condiciones de vida de las comunidades afectadas por proyectos extractivos. ${ }^{67}$

No debe extrañar en este contexto que el Comité para la Eliminación de la Discriminación Racial (CERD) haya reiterado el 2012 su preocupación sobre la falta de aplicación por el Estado canadiense de los derechos de consulta y de CLPI cuando se trata de proyectos que afectan sus tierras, recomendando la adopción de medidas para hacer efectivos estos derechos internacionalmente reconocidos en Canadá ${ }^{68}$.

\footnotetext{
65 Amnesty International, op. cit.

${ }^{66}$ Comunicaciones personales al autor de Viviane Weitzner y Anne Catherine Kennedy, Desarrollo y Paz Canadá, septiembre de 2012.

${ }^{67}$ Amnesty International, op. cit. Un ejemplo de la inefectividad de los IBA para abordar y superar las deplorables condiciones de vida de los pueblos indígenas es el de la comunidad cree de Attawapiskat, del norte de Ontario. La falta de vivienda adecuada, malas condiciones sanitarias y de agua potable existente en ella, que se hicieron públicas por los medios hace poco, son paradójicas para una comunidad que suscribió un IBA con una mina de diamantes distante a 90 kilómetros, mina que recibe importantes utilidades (Mining Watch, op. cit.).

${ }^{68} \mathrm{Al}$ respecto dicho Comité recomendó al Estado de Canadá en marzo de 2012 a que en consulta con los pueblos indígenas:

(a) Implement in good faith the right to consultation and to free, prior and informed consent of Aboriginal peoples whenever their rights may be affected by projects carried out on their lands, as set forth in international standards and the State party's legislation. (Committee on the Elimination of Racial Discrimination (United Nations), Concluding observations on Canada, CERD/C/CAN/CO/18, 25 mayo 2007, para. 20. Disponible en http:// www2.ohchr.org/english/bodies/cerd/cerds70.htm [consultada el 20 de abril de 2012]).
} 


\section{LA RESPONSABILIDAD DE LAS EMPRESAS CANADIENSES POR LA VIOLACIÓN DE LOS DERECHOS HUMANOS DE PUEBLOS INDÍGENAS POR SUS ACTIVIDADES FUERA DE CANADÁ}

En virtud de la importancia que ha adquirido la actividad de las empresas extractivas de recursos naturales canadiense fuera de Canadá, una preocupación creciente al interior de la sociedad canadiense, y fuera de ella, es aquella relativa a la responsabilidad de las empresas canadienses, así como el rol del Estado canadiense frente a las violaciones a los derechos humanos que estas cometen. En efecto, de acuerdo con una investigación comisionada por la Asociación de Prospectores y Desarrolladores de Canadá (PDAC), las compañías canadienses son responsables de tres veces el número de conflictos relacionados a la minería que su par más cercano en este rubro, las compañías australianas. En el caso de América Latina dichas empresas son responsables de casi un tercio de los conflictos registrados. De los incidentes que involucran a compañías canadienses, $60 \%$ están relacionadas con conflictos con la comunidad, $40 \%$ a la degradación ambiental y $30 \%$ a conductas no éticas ${ }^{69}$. Ello es particularmente crítico, como hemos visto, en el caso de América Latina, donde los conflictos de las empresas extractivas canadienses con pueblos indígenas, derivados de la vulneración de sus derechos, son frecuentes.

Como consecuencia de la preocupación de la sociedad civil canadiense, así como de investigaciones y debates parlamentarios en torno a esta materia, el gobierno federal convocó el 2005 a una mesa redonda a distintos actores, incluyendo entre otros a empresas, sociedad civil, académicos y a pueblos indígenas, para analizar la responsabilidad social corporativa de las industrias extractivas canadienses en países en desarrollo. Una de las recomendaciones de esta instancia fue el establecimiento de una Defensoría independiente que investigaría e informaría de casos de reclamos, así como de un Comité de Revisión de Cumplimiento que haría recomendaciones en relación con acciones a adoptar en los casos investigados, las que podrían incluir el retiro de servicios financieros (o no) por parte del gobierno de Canadá frente a casos graves de incumplimiento ${ }^{70}$.

Fue en ese mismo contexto que el Comité para la Eliminación de la Discriminación Racial de la ONU manifestó el 2007 su preocupación sobre la materia, instando a Canadá a adoptar medidas legislativas o administrativas e impedir la afectación negativa de derechos indígenas fuera del país por parte de empresas transnacionales con domicilio recomendando en particular estudiar formas para hacer efectiva su responsabilidad por ello ${ }^{71}$.

${ }^{69}$ Canadian Centre for the Study of Resource Conflict, Corporate social responsibility: Movements and footprints of Canadian mining and exploration firms in the developing world, 2009, en Weitzner, op. cit.

${ }^{70}$ Advisory Group Report, National Roundtables on Corporate Social Responsibility (CSR) and the Canadian Extractive Industry in Developing Countries. March 29, 2007. Disponible en http://www.mining. ca/www/media_lib/MAC_Documents/Publications/CSRENG.pdf [consultada el 20 de abril de 2012].

${ }^{71}$ Committee on the Elimination of Racial Discrimination (United Nations), Concluding observations of the Committee on the Elimination of racial Discrimination,Canada.CERD/C/CAN/CO/19-0. Marzo 9, 2012. http://www2.ohchr.org/english/bodies/cerd/docs/CERD.C.CAN.CO.19-20.pdf. [consultada el 20 de abril de 2012]. 
Lamentablemente las recomendaciones de las mesas redondas nunca fueron implementadas. A cambio de ellas, el gobierno de Canadá hizo pública una nueva iniciativa sobre la materia el 2009, orientada a mejorar la capacidad competitiva de las empresas extractivas canadienses que operan internacionalmente, mediante la potenciación de sus capacidades para manejar conflictos sociales y riesgos ambientales. Entre los pilares de esta iniciativa gubernamental destacan el apoyo a iniciativas de los países en desarrollo en relación con sus capacidades para el impulso de iniciativas mineras, de gas y petróleo, así como con sus capacidades para beneficiarse de dichas actividades y reducir la pobreza; la promoción por diversas instancias de gobiernos de estándares internacionales de responsabilidad social empresarial (CSR por su sigla en inglés), y el establecimiento de una Consejería de CSR para el sector extractivo para asistir a los actores claves vinculados a la actividad de las empresas canadienses fuera de Canadá ${ }^{72}$. Tal Consejería, sin embargo, tiene un mandato limitado que no establece incentivos para que las compañías cambien sus comportamientos. Ello, toda vez que solo revisará, y no investigará reclamos, y ello solo con el consentimiento de las compañías involucradas ${ }^{73}$.

Debido a las limitaciones de esta política es que el 2010 un integrante de la Cámara de los Comunes presentó una iniciativa legal sobre la Responsabilidad Corporativa por las Actividades de la Minería, Petróleo y Gas en Países en Vías de Desarrollo. Dicha iniciativa, conocida como el Bill C-300, establecía un mecanismo de quejas que permitía determinar sanciones, como el retiro de apoyo público y financiero, para empresas que violaran el marco de CSR de Canadá ${ }^{74}$. Lamentablemente esta iniciativa no fue aprobada por estrecho margen por el Parlamento canadiense ${ }^{75}$.

Todo ello determina que Canadá siga sin un marco jurídico y político adecuado para prevenir a sus empresas extractivas de violar derechos humanos fuera de sus fronteras. No es casual entonces, como fuere señalado, que en marzo de 2012 el Comité para la Eliminación de la Discriminación Racial de la ONU haya reiterado su preocupación por las actividades de empresas canadienses, en particular mineras, fuera de Canadá, que resultan en la vulneración de los derechos de pueblos indígenas, volviendo a instar al gobierno a adoptar medidas legislativas y de políticas para impedir dichas violaciones, y para hacer efectiva su responsabilidad por ellas.

${ }^{72}$ Government of Canada (Foreign Affairs and International Trade Canada), Building the Canadian Advantage: A Corporate Social Responsibility (CSR) Strategy for the Canadian International Extractive Sector, 2009. http://www.international.gc.ca/trade-agreements-accords-commerciaux/ds/csr-strategy-rsestategie.aspx?view =d [consultada el 14 de abril de 2012].

73 Weitzner, op. cit. . En los casos hasta ahora analizados por la Consejería, las empresas han decidido retirarse de las mesas de conversación, lo que demuestra la fragilidad de este mecanismo. Comunicación personal de Viviane Weitzner, septiembre de 2012.

${ }^{74}$ Presentada por el miembro del Parlamento John McKay, disponible en http:/www.parl.gc.ca/ HousePublications/Publication.aspx? Docid=3658424\&file $=4 \% 2 \mathrm{ft} \_$blank [consultada el 17 de abril de 2012].

${ }^{75}$ En el rechazo a esta iniciativa habría incidido el intenso lobby de las empresas mineras. Comunicación personal, Jennifer Moore, Mining Watch Canada, septiembre de 2012. 


\section{REFLEXIONES FINALES}

En su reciente intervención en la Cumbre de las Américas en abril pasado en Cartagena de Indias, Colombia, el Primer Ministro de Canadá Stephen Harper manifestó a los jefes de Estado de América Latina su interés de profundizar las inversiones mineras en la región. En la ocasión, junto con identificar los potenciales beneficios de las inversiones mineras proyectadas por Canadá en la región, sostuvo que su país contaba con elevados estándares y principios de responsabilidad y de protección ambiental en el desarrollo de la minería, señalando expresamente que ellos serían aplicables donde quiera que estas fuesen realizadas, y por cierto en América Latina ${ }^{76}$.

Aunque el Primer Ministro Harper no se refirió explícitamente en su intervención a las implicancias de las inversiones mineras, y en general de las inversiones de empresas extractivas canadienses en los territorios indígenas, el análisis realizado en este artículo da cuenta de que tales estándares y principios ambientales y de transparencia no siempre han sido aplicados, no solo en América Latina, sino en muchas ocasiones, en Canadá.

Como también hemos visto en este artículo, el nuevo escenario jurídico referido a los pueblos indígenas que ha emergido como consecuencia de la construcción de un orden supraestatal de los derechos humanos, ha tenido enormes implicancias a nivel global, imponiendo límites al actuar de las empresas extractivas, muchas de ellas de origen canadiense, en tierras y territorios indígenas. Demostrativo de ello en el caso de América Latina son los fallos de la Corte Constitucional de Colombia de 2009 y 2011 que exigen el CLPI de pueblos indígenas antes de la aprobación de grandes proyectos de inversión que afectan sus tierras y territorios, incluyendo entre ellos proyectos mineros y de infraestructura. También demostrativo de lo anterior es el reciente fallo de la Corte Suprema de Chile que anuló la resolución ambiental que aprobó el proyecto minero El Morro impulsado por la empresa canadiense GoldCorp en tierras indígenas, mientras no se desarrollen procesos de consulta con miras a lograr el consentimiento de la comunidad diaguita directamente afectada, y mientras no se considere la participación de dicha comunidad en los beneficios de esta iniciativa, según los estándares del Convenio 169 de la OIT.

Lo mismo puede señalarse en el caso canadiense, en donde la jurisprudencia de la Corte Suprema ha obligado crecientemente a los gobiernos a la consulta y a la acomodación de intereses frente a actividades susceptibles de afectar adversamente los derechos de los pueblos indígenas sobre sus tierras y recursos. Donde además los órganos de los tratados de los que este Estado es parte, como la Convención para la Eliminación de todas las Formas de Discriminación Racial, han conminado al Estado canadiense a consultar

${ }^{76}$ En esa oportunidad el Primer Ministro de Canadá señaló:

... let nobody doubt for a moment that responsible resource development and environmental protection remain core Canadian principles. Indeed, principles which have led Canada to develop some of the most effective environmental regulations and most transparent monitoring programs in the world. And we expect that these principles will be respected, not just in Canada, but wherever Canadian mining companies and miners work around the world. (Harper, op. cit.). 
y a obtener el CLPI de pueblos indígenas cuando sus derechos sean impactados negativamente por proyectos llevados adelante en sus tierras ancestrales.

Resulta evidente entonces que tanto los Estados latinoamericanos como Canadá deberán revisar su política y marcos normativos internos referidos a los derechos de los pueblos indígenas para adecuarlos a las obligaciones internacionales de derechos humanos que han contraído. Dichos Estados tendrán que aceptar que la globalización es un fenómeno complejo, que va mucho más allá de los mercados. Tendrán que aceptar igualmente, por lo mismo, que los mercados no pueden seguir expandiéndose sin un respeto por los derechos de las personas y de los pueblos, incluyendo por cierto a los pueblos indígenas, cuyos territorios han impactado de forma notable las industrias extractivas en las últimas décadas.

\section{BIBLIOGRAFÍA}

Advisory Group Report, National Roundtables on Corporate Social Responsibility (CSR) and the Canadian Extractive Industry in Developing Countries. March 29, 2007. Disponible en http:// www.mining.ca/www/media_lib/MAC_Documents/Publications/CSRENG.pdf [consultada el 20 de abril de 2012].

Amnesty International, Canada. Briefing to the UN Committee on the Elimination of Racial Discrimination, 80th Session. Febrero de 2012. Disponible en http://www2.ohchr.org/english/ bodies/cerd/docs/ngos/AI_CANADA_CERD80.pdf [consultada el 21 de abril de 2012].

ANAYA, J., La situación de los pueblos indígenas en Colombia: Seguimiento a las recomendaciones hechas por el Relator Especial anterior. Naciones Unidas, A/HRC/15/34 8 de enero de 2010.

Arellano, J.M., Canadian Foreign Direct Investment in Latin America. The North South Institute, Ottawa, 2010. Disponible en http://www.nsi-ins.ca/english/pdf/FDI\%20backgrounder.pdf [consultada el 10 de marzo de 2012].

Bello, A. y Rangel, M., Etnicidad, "raza" y equidad en América Latina y el Caribe. CEPAL, Santiago, 2000.

Canadian Centre for Community Renewal et al., Aboriginal Minig Guide, 2009. Disponible en http://www.miningguide.ca/sites/all/files/AMG_CaseStudy2_Raglan_online.pdf [consultada el 3 de abril de 2012].

Canadian Centre for the Study of Resource Conflict (CCSRC), Corporate social responsibility: Movements and footprints of Canadian mining and exploration firms in the developing world, 2009.

Committee on the Elimination of Racial Discrimination (United Nations), Concluding observations on Canada, CERD/C/CAN/CO/18, mayo 25, 2007. Disponible en http://www2. ohchr.org/english/bodies/cerd/cerds70.htm [consultada el 20 de abril de 2012].

Committee on the Elimination of Racial Discrimination (United Nations), Concluding observations of the Committee on the Elimination of racial Discrimination, Canada.CERD/C/CAN/ CO/19-0. Marzo 9, 2012. Disponible en http://www2.ohchr.org/english/bodies/cerd/docs/ CERD.C.CAN.CO.19-20.pdf. [consultada el 20 de abril de 2012].

De ECHAVE, J., ¿Invitados a la mesa grande? El crecimiento del sector extractivo, la participación indígenal campesina en procesos multiactorales y presencia canadiense en el Perú. Cooper Action, Lima; North South Institute, Ottawa, 2011. Disponible en http://www.nsi-ins.ca/images/documents/ peru_spanish_2011_final_web.pdf [consultada el 2 de abril de 2012]. 
Drake, A., Overview of trends in Canadian minerals exploration, Natural Resources Canada, Ottawa, 2010, en Weitzner, V., Inclinando la balanza del poder. Logrando que el consentimiento libre, previo e informado funcione. North South Institute, Ottawa, 2011.

Engler, Y., "Canada’s New Territory? Mining Peru”, 2010. Disponible en http://www.counterpunch.org/2010/12/23/mining-peru/ [consultada el 20 de marzo de 2012].

Fidler, Courtney y Hiтch, Michael, "Impact Benefit Agreements: A contentious issue for environmental and aboriginal justice". En Environmental Journal 35 (2) 2007, 49-69. Disponible en http://cbern.sharpschool.com/kr/One.aspx?objectId = 10486948\&contextId =677979\&la stCat $=10486919$ [consultada el 14 de abril de 2012].

Gibson, G. y O'Faircheallaigh, C. IBA Community Toolkit. Negotiation and Implementation of Impact benefit Agreements. Walter \& Duncan Gordon Foundation, Toronto: 2010.

Gobierno de Chile, Evaluación de las Relaciones Comerciales entre Chile y Canadá a Doce años de la Entrada en Vigencia del TLC, julio 2009. Disponible en http://www.sice.oas.org/TPD/ CAN_CHL/studies/Eval2008_s.pdf [consultada el 30 de marzo de 2012].

Government of Canada, Aboriginal Consultation and Accommodation, Updated Guidelines for Federal Officials to Fulfil the Duty to Consult. Minister of the Department of Indian Affairs and Northern Development, Ottawa. 2011.

Government of CANADA (Foreign Affairs and International Trade Canada), Building the Canadian Advantage: A Corporate Social Responsibility (CSR) Strategy for the Canadian International Extractive Sector, 2009. http://www.international.gc.ca/trade-agreements-accords-commerciaux/ds/ csr-strategy-rse-stategie.aspx?view =d [consultada el 14 de abril de 2012].

Government of Canada (Minister of Indian Affairs and Northern Development), Aboriginal Self-Government. The Government of Canada's Approach to Implementation of the Inherent Right and the Negotiation of Aboriginal Self-Government, DIAND, Ottawa, 1995.

HARPER, S. "Looking to the future, we see increased Canadian mining investment throughout the Americas, something that will be good for our mutual prosperity and is therefore a priority of our Government.", Statement by the Prime Minister of Canada in Cartagena, Colombia. Disponible enhttp://www.pm.gc.ca/eng $/$ media.asp? category $=3 \&$ featureId $=6 \& p$ ageId $=26 \&$ id $=4742$ [consultada el 28 de abril de 2012].

Land Claims Agreements Coalition, Submission to the Standing Committee on Aboriginal Affairs and Northern Development May 12, 2009 "A Legacy of Colonialism and Paternalism". Disponible en http://www.landclaimscoalition.ca/pdf/090504-LCAC_Submission_to_AANO-Final.pdf [consultada el 3 de abril de 2012].

Mining Watch Canada, Fundamental Improvements Needed; The Mining Sector and Indigenous Rights in Canada. Submisssion on Canada's 19 tth and 20th Periodic Reports to The Committee on the Elimination of Racial Discrimination, enero de 2012. Disponible en http://www2.ohchr. org/english/bodies/cerd/docs/ngos/MW_Canada80.pdf [consultada el 20 de abril de 2012].

Pain, I. y Paddon, T. Negotiating Agreements: Indigenous And Company Experiences: Presentation Of The Voisey's Bay Case Study From Canada, International Seminar on Natural Resource Companies, Indigenous Peoples and Human Rights: Setting a Framework for Consultation, benefit Sharing and Dispute Resolution. Moscu, Diciembre de 2008. Disponible en http://www.ohchr.org/Documents/ Issues/IPeoples/Seminars/Vale_Inco_Canada_Voiseys_Bay_case_Moscow_Workshop.pdf [consultada el 15 de abril de 2012].

PEÑA, N., "Canadá desplaza a EE.UU. como mayor inversor en Chile en última década", en $L a$ Tercera, enero 28, 2012, p. 55.

Programa de Naciones Unidas Para el Desarrollo (PNUD), Segundo informe sobre desarrollo bumano en Centroamérica y Panamá, PNUD, San José de Costa Rica, 2003. 
Randall, J.C., "Canada, the Caribbean and Latin America: Trade, Investment and Political Challenges," en Canadian International Council, Agosto 2010. Disponible en http://www. opencanada.org/wp- content/uploads/2011/05/Canada-the-Caribbean-and-Latin-America_Trade-Investment-and-Political-Challenges-Stephen-J.-Randall.pdf. [consultada el 13 de marzo de 2012].

Ross, J., “Canadian mining companies undermining Mexico”, 2009. Disponible http://mostlywater. org/canadian_mining_companies_undermining_mexico [consultada el 18 de marzo de 2012].

StAVEnHagen, R., Report of the Special Rapporteur on the situation of human rights and fundamental freedoms of indigenous people, Rodolfo Stavenhagen* Addendum, United Nations. E/CN.4/2006/78/ Add. 5 17, enero de 2006.

STAVEnHaGen, R., Report of the Special Rapporteur on the situation of human rights and fundamental freedoms of indigenous people, Rodolfo Stavenhagen. Addendum MISSION TO CANADA, E/CN.4/2005/88/ Add.3, 2004.

YRIGOYEN, R., "El horizonte del constitucionalismo pluralista; del multiculturalismo a la descolonización”, en Rodríguez, C. (Coord.), El derecho en América Latina. Un mapa para el pensamiento jurídico del siglo XXI, Siglo XXI Ed., México D.F., 2011, pp. 139-160.

Weitzner, V., Inclinando la balanza del poder. Logrando que el consentimiento libre, previo e informado funcione, North South Institute, Ottawa, 2011.

Zaffaroni, E.R., "La naturaleza como persona: Pachamama y Gaia", en Calizaya, A. y Zaffaroni, E.R., Nuevo constitucionalismo ambiental (Perspectivas desde lo plurinacional comunitario). Latinas Editores, Uru uru Marka, 2009, pp. 35-62. 
